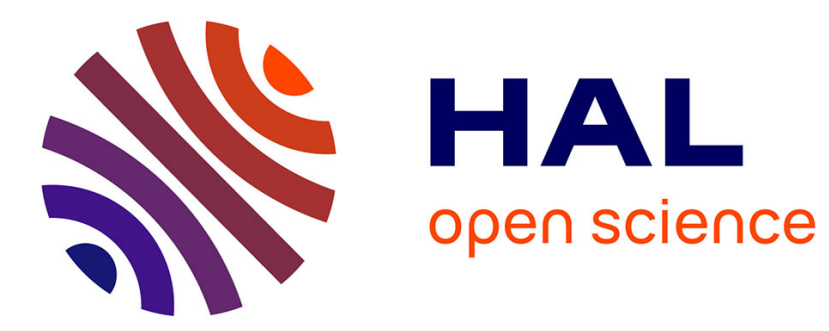

\title{
Sol-Gel Chemistry of Titanium Alkoxide toward HF: Impacts of Reaction Parameters
}

Wei Li, Monique Body, Christophe Legein, Damien Dambournet

\section{To cite this version:}

Wei Li, Monique Body, Christophe Legein, Damien Dambournet. Sol-Gel Chemistry of Titanium Alkoxide toward HF: Impacts of Reaction Parameters. Crystal Growth \& Design, 2016, 16 (9), pp.5441 - 5447. 10.1021/acs.cgd.6b00910 . hal-01489147

\section{HAL Id: hal-01489147 https://hal.sorbonne-universite.fr/hal-01489147}

Submitted on 14 Mar 2017

HAL is a multi-disciplinary open access archive for the deposit and dissemination of scientific research documents, whether they are published or not. The documents may come from teaching and research institutions in France or abroad, or from public or private research centers.
L'archive ouverte pluridisciplinaire HAL, est destinée au dépôt et à la diffusion de documents scientifiques de niveau recherche, publiés ou non, émanant des établissements d'enseignement et de recherche français ou étrangers, des laboratoires publics ou privés. 


\title{
Sol-gel Chemistry of Titanium alkoxide towards HF: impacts of reaction parameters
}

\author{
Wei Li, ${ }^{\dagger}$ Monique Body, ${ }^{\S}$ Christophe Legein, ${ }^{\S}$ and Damien Dambournet ${ }^{t, *}$ \\ † Sorbonne Universités, UPMC Univ Paris 06, CNRS, Laboratoire PHENIX, Case 51, 4 place \\ Jussieu, F-75005 Paris, France \\ $\S$ Université Bretagne Loire, Université du Maine, UMR CNRS 6283, Institut des Molécules et \\ des Matériaux du Mans (IMMM), Avenue Olivier Messiaen, 72085 Le Mans Cedex 9, France
}

KEYWORDS. Fluorolysis, hydrolysis, anatase, hexagonal-tungsten-bronze, oxyhydroxyfluoride, titanium vacancies, ${ }^{19} \mathrm{~F}$ solid state NMR.

ABSTRACT. The sol-gel chemistry of titanium-based oxide prepared in a fluorinated medium leads to oxy-hydroxyfluorinated framework owing to the occurrence of both hydrolysis and fluorolysis reactions. Here, a systematic study was carried out to investigate the impact of the sol-gel synthesis parameters on the reaction of titanium alkoxides and HF. This study provides comprehensive insights of the sol-gel process in a fluorinated medium. Depending on the extend of fluorination, two types of structures can be stabilized including an anatase $\mathrm{Ti}_{1-x-y} \square_{x+y} \mathrm{O}_{2-}$ ${ }_{4(\mathrm{x}+\mathrm{y})} \mathrm{F}_{4 \mathrm{x}}(\mathrm{OH})_{4 \mathrm{y}}$ and a fluoride-rich $\mathrm{HTB} \mathrm{Ti}_{1-\mathrm{x}} \square_{\mathrm{x}} \mathrm{O}_{1-4 \mathrm{x}}(\mathrm{F}, \mathrm{OH})_{2+4 \mathrm{x}}$ phases, where $\square$ refers to titanium vacancies. The reactivity of titanium alkoxide in alcohol toward HF has been shown to mostly depend on the solvent characteristics highlighting an alcohol interchange reaction 
between the titanium precursor and the solvent. Increasing the fluorine concentration leads to a structural change from the anatase to the fluoride-rich HTB phase which is rationalized by the preferential linking modes of Ti octahedral subunits in relation with its anionic environment, i.e. corner-sharing configuration is favored for $\mathrm{Ti}^{4+}$ in a fluorinated environment. Finally, ${ }^{19} \mathrm{~F}$ MAS NMR spectroscopy has allowed to identify the different species involved in the stabilized phases providing spectroscopic signatures to further investigate these complex compounds.

\section{Introduction}

The chemistry of the sol-gel process relies on the hydroxylation and condensation of molecular precursors. ${ }^{1}$ The reactivity of metal alkoxide toward solvents or additives can yielded new molecular precursors and thus to a large panel of composition and structures. ${ }^{2-4}$ The chemistry of titanium is a good example of the versatility of the sol-gel process to produce new materials with tailored architecture and properties. ${ }^{5,6}$ One of the approaches used to tailor crystal's properties is to play on the complexing ability of anions. For instance, fluoride anions have been shown to play many roles such as driving the nucleation/crystallization toward a specific crystal's structure. ${ }^{7,8}$ They can also adsorb onto surfaces thus orienting, in a particular direction, the growth of particles. ${ }^{9,10}$ More recently, the reaction of titanium alkoxide with aqueous HF has yielded to the precipitation under mild solvothermal conditions to an oxy-hydroxy-fluoride compound $\mathrm{Ti}_{1-\mathrm{x}-\mathrm{y}} \square_{\mathrm{x}+\mathrm{y}} \mathrm{O}_{2-4(\mathrm{x}+\mathrm{y})} \mathrm{F}_{4 \mathrm{x}}(\mathrm{OH})_{4 \mathrm{y}}$ featuring the anatase type structure with titanium vacancies $(\square) .{ }^{11}$ This result has highlighted the occurrence of a fluorolysis ${ }^{12,13}$ reaction between titanium alkoxide and $\mathrm{HF}$ according to $\mathrm{Ti}(\mathrm{OR})_{\mathrm{n}}+\mathrm{xHF} \rightarrow \mathrm{Ti}(\mathrm{OR})_{\mathrm{n}-\mathrm{x}} \mathrm{F}_{\mathrm{x}}+\mathrm{xROH} .{ }^{11,14}$ Hence, the functionalization of titanium alkoxide by fluoride can open new opportunities in the sol-gel 
chemistry of titanium-based compounds providing that a good understanding of the impact of the synthesis parameters is achieved.

Herein, we investigate the effects of synthesis parameters (nature of solvent, alkoxide precursor, HF concentration) on the structure and chemical composition of the precipitated phase obtained by mild solvothermal synthesis. It provides a better understanding on how the synthesis parameters impact on the chemical reactivity of titanium alkoxide toward HF. Two types of phases were synthetized including an anatase $\mathrm{Ti}_{1-\mathrm{x}-\mathrm{y}} \square_{\mathrm{x}+\mathrm{y}} \mathrm{O}_{2-4(\mathrm{x}+\mathrm{y})} \mathrm{F}_{4 \mathrm{x}}(\mathrm{OH})_{4 y}$ and a fluoride-rich hexagonal-tungsten-bronze (HTB) $\mathrm{Ti}_{1-\mathrm{x}} \square_{\mathrm{x}} \mathrm{O}_{1-4 \mathrm{x}}(\mathrm{F}, \mathrm{OH})_{2+4 \mathrm{x}}$ phase. This work provides also guidelines to tune the chemical composition of these phases.

\section{Experimental Section}

Synthesis. Titanium ethoxide $\mathrm{Ti}\left(\mathrm{OCH}_{2} \mathrm{CH}_{3}\right)_{4} \quad\left(\mathrm{Ti}(\mathrm{OEt})_{4}\right)$, titanium isopropoxide $\mathrm{Ti}\left(\mathrm{OCH}\left(\mathrm{CH}_{3}\right)_{2}\right)_{4}$, $\left(\mathrm{Ti}(\mathrm{OiPr})_{4}\right)$, titanium butoxide $\mathrm{Ti}\left(\mathrm{OCH}_{2} \mathrm{CH}_{2} \mathrm{CH}_{2} \mathrm{CH}_{3}\right)_{4}\left(\mathrm{Ti}(\mathrm{OBu})_{4}\right)$, ethanol $(\mathrm{EtOH})$, isopropanol $(\mathrm{PriOH})$ and 2-butanol $(2-\mathrm{BuOH})$ were purchased from Sigma-Aldrich and used as received. Aqueous HF (40\%) was purchased from Rectapur. Caution: HF solution is highly hazardous and special protective equipments are required.

In a typical synthesis, 13.5 mmol of titanium alkoxide precursor were poured inside a Teflon liner cup, then a solution containing aqueous hydrofluoric acid and alcohol was added under stirring. The volume of HF added depends on the fixed molar ratio of $\mathrm{R}=\mathrm{F} / \mathrm{Ti}$. The volume of the alcohol was adjusted so that the total volume of the solution equals $30 \mathrm{~mL}$. The Teflon liner cup was placed inside a stainless steel autoclave and then heated in an oven at $90{ }^{\circ} \mathrm{C}$ for $12 \mathrm{~h}$. After the reaction, the autoclave was left to cool down to room temperature. The resulting white precipitate was washed twice with ethanol and subsequently recovered by centrifugation at 4400 rpm for 15 min. Finally, the powder was dried at $80^{\circ} \mathrm{C}$ for $2 \mathrm{~h}$. 
Characterization methods. X-ray powder diffraction analysis was carried out using a Rigaku Ultima IV X-ray diffractometer equipped with a $\mathrm{Cu} \mathrm{K}_{\alpha}$ radiation source $(\lambda=1.54059 \AA)$.

Transmission Electron Microscopy analysis was performed using a JEOL 2010 UHR microscope operating at $200 \mathrm{kV}$ equipped with a TCD camera.

${ }^{19} \mathrm{~F}$ solid-state magic angle spinning (MAS) NMR experiments were performed on a Bruker Avance III spectrometer operating at $7.0 \mathrm{~T}\left({ }^{19} \mathrm{~F}\right.$ Larmor frequency of $\left.282.2 \mathrm{MHz}\right)$, using a 2.5 and/or a $1.3 \mathrm{~mm}$ CP-MAS probe head. The ${ }^{19} \mathrm{~F}$ MAS spectra were recorded using a Hahn echo sequence with an interpulse delay equal to one rotor period. The $90^{\circ}$ pulse length was set to 1.55 $\mu \mathrm{s}(2.5 \mu \mathrm{s})$ and the recycle delay was set to $20 \mathrm{~s}(10 \mathrm{~s})$ for the spectra recorded with $1.3 \mathrm{~mm}(2.5$ $\mathrm{mm})$ probe head. ${ }^{19} \mathrm{~F}$ spectra are referenced to $\mathrm{CFCl}_{3}$ and were fitted by using the DMFit software. ${ }^{15}{ }^{19} \mathrm{~F}$ solid state NMR was also used to quantify the fluorine content on some of the studied samples by using the $1.3 \mathrm{~mm}$ probe head and reference samples. ${ }^{11,14}{ }^{19} \mathrm{~F}$ solid-state MAS NMR (Hahn echo) spectra were also recorded for $\mathrm{YF}_{3}$ and $\mathrm{LaF}_{3}$ and the masses of each sample in the rotor were measured. The fits of the spectra allow to determine the integrated intensities (I) for each sample. Since, for each sample, the recycle delays were chosen to ensure that the amount of signal detected is maximum ( $420 \mathrm{~s}_{\text {for }} \mathrm{YF}_{3}$ and $120 \mathrm{~s}$ for $\left.\mathrm{LaF}_{3}\right)$, we assume that the integrated intensities are proportional to the number of scans (256 for the studied samples and 16 for $\mathrm{YF}_{3}$ and $\mathrm{LaF}_{3}$ ) and to the molar quantity of fluorine atoms (n) in the rotor. This assumption is verified since the calculated $\mathrm{I} / \mathrm{n}$ ratio for $\mathrm{YF}_{3}$ and $\mathrm{LaF}_{3}$ are equal. The intensities per scan of the NMR signals of the studied samples, $\mathrm{I}_{1}$, and of $\mathrm{YF}_{3}\left(\right.$ or $\left.\mathrm{LaF}_{3}\right), \mathrm{I}_{2}$, allow to calculate the fluorine wt. \% in the studied samples using the following formula where $\mathrm{m}$ and $\mathrm{M}$ are the mass and the molar mass, respectively: 


$$
\begin{gathered}
\frac{I_{1}}{I_{2}}=\frac{n_{F}}{\frac{3 m_{Y F_{3}}}{M_{Y F_{3}}}} \\
F w t . \%=\frac{m_{F}}{m}=\frac{n_{F} M_{F}}{m}=\frac{3 m_{Y F_{3}}}{M_{Y F_{3}}} \frac{\mathrm{I}_{2}}{\mathrm{I}_{2}} \frac{\mathrm{M}_{\mathrm{F}}}{\mathrm{m}}
\end{gathered}
$$

\section{Results and Discussion}

Effect of the nature of the solvent. In a previous study, we have demonstrated that the solvothermal reaction of titanium isopropoxide dissolved in its parent alcohol with aqueous HF $(\mathrm{R}=\mathrm{F} / \mathrm{Ti}=2)$ yields to an oxy-hydroxyfluoride $\mathrm{Ti}_{1-\mathrm{x}-\mathrm{y}} \square_{\mathrm{x}+\mathrm{y}} \mathrm{O}_{2-4(\mathrm{x}+\mathrm{y})} \mathrm{F}_{4 \mathrm{x}}(\mathrm{OH})_{4 \mathrm{y}}$ (the accurate chemical composition being $\mathrm{Ti}_{0.78} \square_{0.22} \mathrm{O}_{1.12} \mathrm{~F}_{0.40}(\mathrm{OH})_{0.48}$ ) featuring the anatase type structure with titanium vacancies $(\square) .{ }^{11}$ Therein, the influence of the solvent was investigated by using other solvents featuring shorter and longer alkyl chains, i.e. ethanol and 2-butanol. The other operating conditions were fixed as defined previously. Figure 1 shows the XRD patterns of the samples obtained using different solvents.

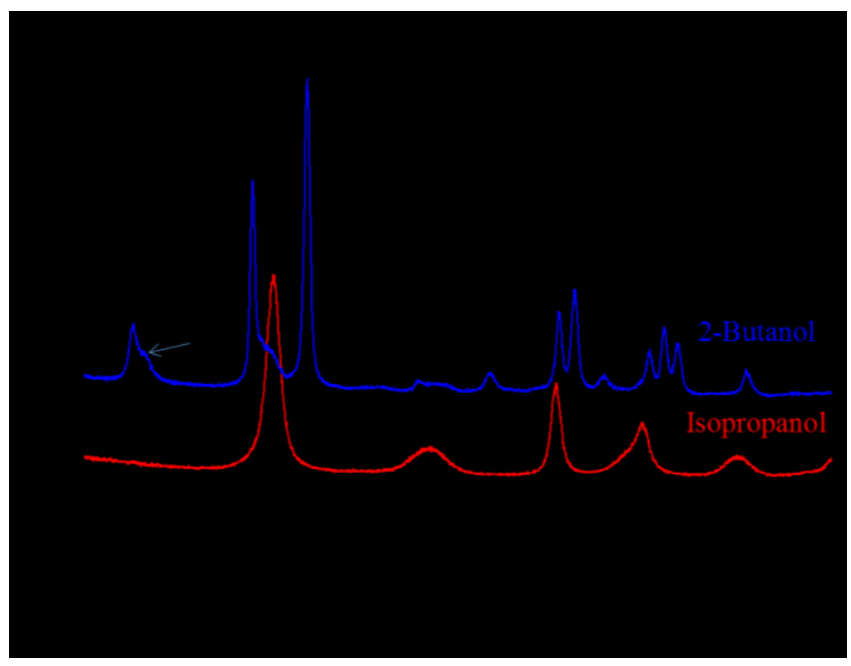

Figure 1. XRD patterns of the samples prepared using ethanol (black), isopropanol (red) and 2butanol (blue) as solvent. Titanium isopropoxide was used as precursor and a molar ratio R was 
set to 2 . 'A' and 'HTB' refer to anatase and hexagonal-tungsten-bronze type phases, respectively and asterisk refers to (200) planes of $\mathrm{TiO}_{2}-\mathrm{B}$.

Samples prepared with ethanol and isopropanol display similar XRD patterns indexed with a tetragonal unit cell (space group $\mathrm{I}_{1} / \mathrm{amd}$ ) characteristic of $\mathrm{TiO}_{2}$ anatase. As discussed later, detailed analyses performed on these anatase phases revealed a complex composition $\mathrm{Ti}_{1-\mathrm{x}}$ ${ }_{y} \square_{x+y} \mathrm{O}_{2-4(x+y)} F_{4 x}(O H)_{4 y}$ with a degree of fluorination, i.e. vacancies, that increases from ethanol to isopropanol. Moreover, the use of 2-butanol yields a completely different XRD pattern with peaks characteristic of a fluoride-rich phase crystallizing in the HTB type structure (space group $\left.\mathrm{P} 6_{3} / \mathrm{mmc}\right) .{ }^{16}$ A peak located at $15.1^{\circ}(2 \theta)$ indicates the presence of a minor phase identified as $\mathrm{TiO}_{2}-\mathrm{B}$ (space group $\mathrm{C} 2 / \mathrm{m}$ ). Figure 2 shows the structural representation of the three phases. Thus, it can be concluded that the chemical reactivity of HF toward titanium alkoxide is strongly influenced by the nature of the solvent, particularly the length of the alkyl chains. It is known that when titanium alkoxides are dissolved into alcohol solvent, an exchange of alkoxy groups takes place by substitution reaction, modifying the molecular structure of the Ti precursor and consequently its chemical reactivity., ${ }^{2,317}$ This reaction is known as an alcohol interchange reaction: $T i(O R)_{n}+x R^{\prime} O H \leftrightarrows T i(O R)_{n-x}\left(O R^{\prime}\right)_{x}+x R O H$. While the high electrophilic character of titanium favors the reaction, the steric hindrance of the alkoxy group decreases ligand interchange. ${ }^{2}$ 
a

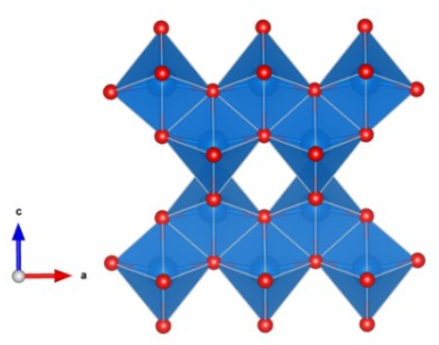

b

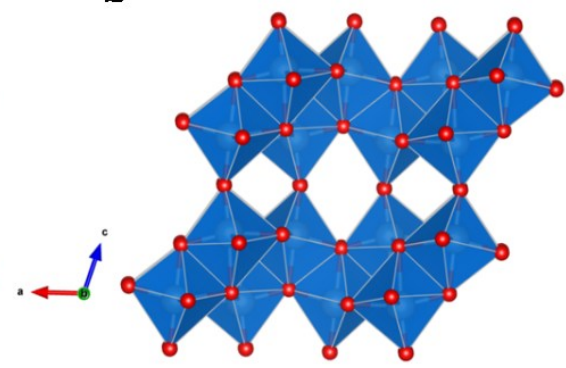

c

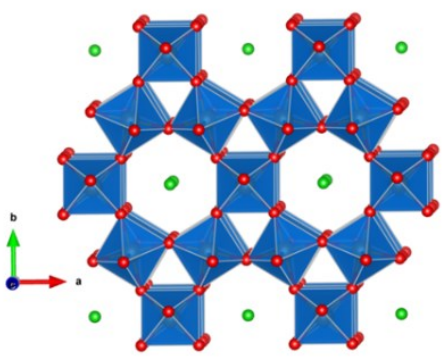

Figure 2. Structural representation of (a) $\mathrm{TiO}_{2}$ anatase, (b) $\mathrm{TiO}_{2}-\mathrm{B}$ and (c) hexagonal tungsten bronze (HTB) framework.

The predominant effect between the alcohol interchange reactions and the initial molecular structure of the alkoxide precursor was also investigated by varying the nature of Ti precursors while fixing the other operating conditions. Figure 3 shows the XRD patterns of the samples obtained by using $\mathrm{Ti}(\mathrm{OBu})_{4}$ and $\mathrm{Ti}\left(\mathrm{O}^{\mathrm{i} P r}\right)_{4}$ as precursor. The solvent was butanol and the molar ratio $\mathrm{R}$ was fixed to 2 . In both cases, $\mathrm{XRD}$ patterns showed the main presence of the fluoriderich phase having the HTB type structure. Thus, the nature of the precursor has little influence on the structure of the final products.

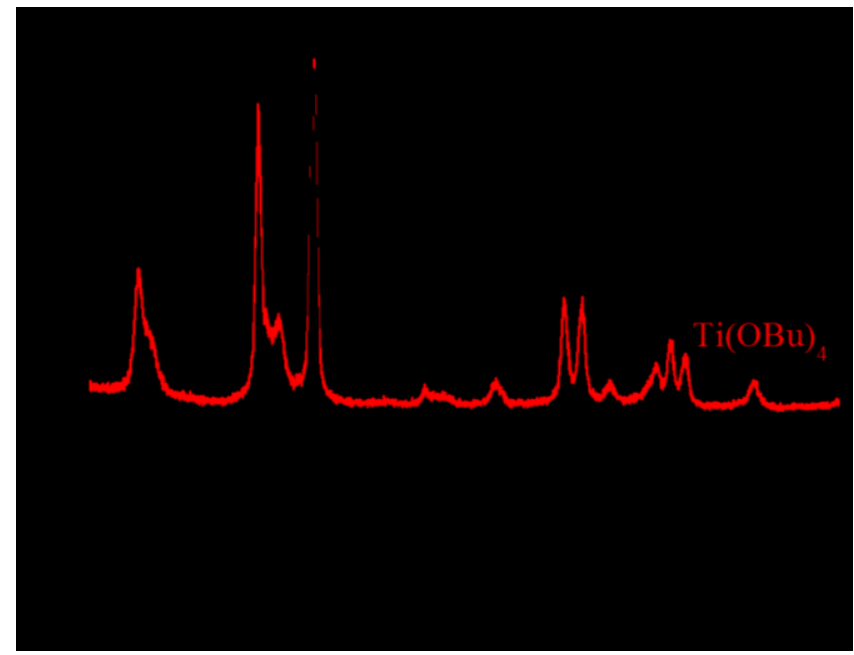


Figure 3. XRD patterns of the samples prepared using two different alkoxide precursors, $\mathrm{Ti}\left(\mathrm{O}^{\mathrm{i}} \mathrm{Pr}\right)_{4}$ (black) and $\mathrm{Ti}(\mathrm{OBu})_{4}$ (red). The solvent and fluorine content are 2-butanol and $\mathrm{R}=2$, respectively. 'HTB' refers to hexagonal-tungsten-bronze type phase and asterisk refers to (200) planes of $\mathrm{TiO}_{2}-\mathrm{B}$.

The above results indicate that due to ligand interchange reactions between the solvent and the titanium precursor, it is the solvent characteristics and particularly the length of the alkyl chains that rules the composition/structure of the final stabilized phase. Thus, ethoxide, isopropoxide and butoxide ligands can be stabilized in the vicinity of $\mathrm{Ti}^{4+}$ when ethanol, isopropanol and butanol are used as solvents, respectively. Moreover, the stabilization of a higher fluorine concentration in the precipitated phase using solvent with longer alkyl chains indicates that the competition between hydrolysis and fluorolysis reaction is ruled by the structure of the molecular precursor. It has been reported that the reactivity of alkoxides towards water increases when the length of the alkyl chains decreases: $\mathrm{OEt}^{-}>\mathrm{OiPr}^{-}>\mathrm{OBu}^{-1,18}$ Shorter alkyl chains lead to the increase of the positive partial charge of $\mathrm{Ti}$, thus $\mathrm{Ti}$ atoms become more reactive towards nucleophilic attack. Moreover, long alkyl chains exert steric hindrance during the nucleophilic substitution. Since $\mathrm{HF}$ and $\mathrm{H}_{2} \mathrm{O}$ display similar nucleophilic characters, i.e., the partial charges are $\delta(\mathrm{F})=-0.42$ in $\mathrm{HF}$ and $\delta(\mathrm{O})=-0.40$ in $\mathrm{H}_{2} \mathrm{O},{ }^{1}$ the difference in reactivity can be related to higher steric hindrance of water molecule as compared to HF. For longer alkyl chains, the fluorination is thus favored over hydrolysis. The rate of hydrolysis reaction decreases while the size of alkoxy group increases.

To further understand the reactivity of titanium alkoxide toward $\mathrm{HF},{ }^{19} \mathrm{~F}$ solid state MAS NMR spectra were recorded on two reference samples having the HTB and anatase type structure (Figure 4). A pure HTB phase was synthetized using the following conditions $\mathrm{R}=3.7$, solvent: 
2-butanol, precursor: titanium butoxide (see later). The anatase phase $\operatorname{Ti}_{0.78} \square_{0.22} \mathrm{O}_{1.12} \mathrm{~F}_{0.40}(\mathrm{OH})_{0.48}$ was synthetized using previously established conditions: $\mathrm{R}=2.0$, solvent: isopropanol, precursor : titanium isopropoxide. ${ }^{11}$ Fluorine quantification of these samples yielded 27.4 and 10.8 wt. \% for the HTB and anatase type phase, respectively.

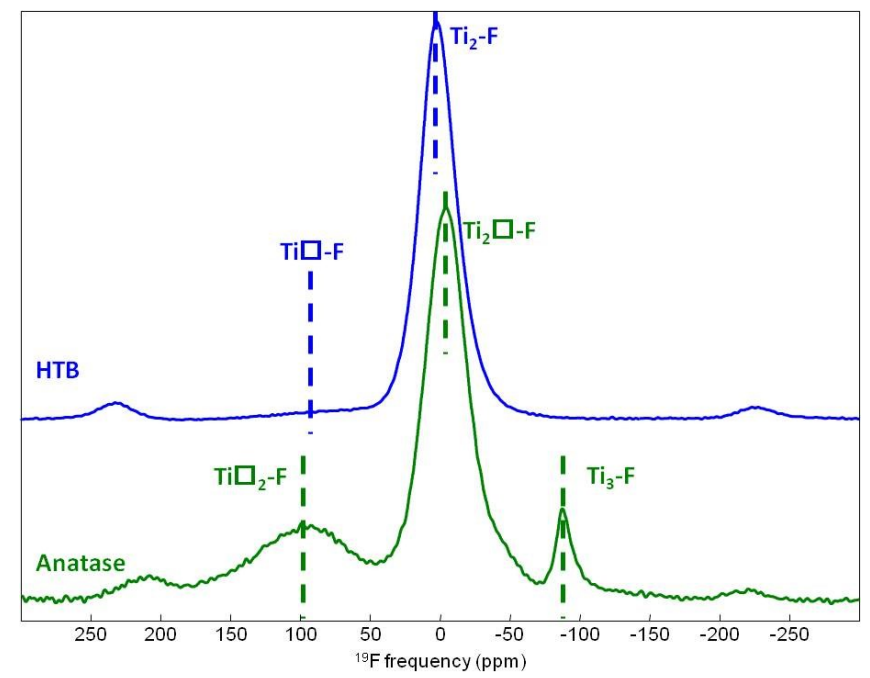

Figure 4. ${ }^{19} \mathrm{~F}$ MAS (64 kHz and $60 \mathrm{kHz}$, respectively) solid state NMR spectra of the pure HTB phase synthesized using the following conditions $\mathrm{R}=3.7$, solvent: 2-butanol, precursor: titanium butoxide (blue) and of the anatase phase $\operatorname{Ti}_{0.78} \square_{0.22} \mathrm{O}_{1.12} \mathrm{~F}_{0.40}(\mathrm{OH})_{0.48}$ synthetized using the following conditions: $\mathrm{R}=2.0$, solvent: isopropanol, precursor : titanium isopropoxide (green). The blue dashed lines indicate the two main lines assigned to $\mathrm{Ti}_{2}-\mathrm{F}$ and $\mathrm{Ti} \square-\mathrm{F}$ environments in the HTB phase and the green dashed lines indicate the three main lines assigned to $\mathrm{Ti}_{3}-\mathrm{F}, \mathrm{Ti}_{2} \mathrm{D}-\mathrm{F}$ and $\mathrm{Ti} \square_{2}-\mathrm{F}$ environments in the anatase phase.

The ${ }^{19} \mathrm{~F}$ solid state MAS NMR spectrum of $\mathrm{Ti}_{0.78} \square_{0.22} \mathrm{O}_{1.12} \mathrm{~F}_{0.40}(\mathrm{OH})_{0.48}$ features three main lines previously assigned to fluorine atoms in the vicinity of different numbers of titanium atoms and/or titanium vacancies, i.e. species $\mathrm{Ti}_{3}-\mathrm{F}$ at $-88 \mathrm{ppm}, \mathrm{Ti}_{2} \square-\mathrm{F}$ at $-4 \mathrm{ppm}$ and $\mathrm{Ti}_{2}-\mathrm{F}$ at 98 ppm. ${ }^{11}$ The spectrum of the HTB phase shows two main contributions emphasizing two types of local environments for $\mathrm{F}$ atoms. The most intense was reconstructed with three NMR resonances 
located at $\sim-7,3$ and $27 \mathrm{ppm}$ and the less intense was reconstructed with one broad NMR resonance located at $\sim 90 \mathrm{ppm}$ (Figure $\mathrm{S} 1$ and Table S1). Within pure $\mathrm{HTB}_{\mathrm{TiOF}}$, an anion is surrounded by two titanium atoms and the isotropic chemical shifts of the most intense contribution are close to those measured for $\mathrm{Ti}_{2} \square-\mathrm{F}$ environments in anatase $\mathrm{Ti}_{0.78} \square_{0.22} \mathrm{O}_{1.12} \mathrm{~F}_{0.40}(\mathrm{OH})_{0.48} \quad\left(-4 \quad \mathrm{ppm}^{11}\right)$ and for $\mathrm{Ti}_{2}-\mathrm{F}$ environments in $\mathrm{ReO}_{3}$ type $\mathrm{Ti}_{0.90} \square_{0.10} \mathrm{O}_{0.60}(\mathrm{OH})_{0.74} \mathrm{~F}_{1.66}\left(12\right.$ and $\left.20 \mathrm{ppm}^{19}\right)$. This line is then assigned to $\mathrm{Ti}_{2}-\mathrm{F}$ environments. The isotropic chemical shift of the less intense line is close to those measured for $\operatorname{Ti} \square_{2}-\mathrm{F}$ environments in anatase $\mathrm{Ti}_{0.78} \square_{0.22} \mathrm{O}_{1.12} \mathrm{~F}_{0.40}(\mathrm{OH})_{0.48}\left(98 \mathrm{ppm}^{11}\right)$ and for terminal $\mathrm{F}$ in $\mathrm{K}_{2} \mathrm{TiF}_{6}$ $\left(71.4 \mathrm{ppm}^{20}\right)$ and in hybrid hydroxyfluorotitanates (IV) $\left(76\right.$ to $\left.82 \mathrm{ppm}^{21}\right)$ showing the occurrence of a small amount of Ti $\square$-F environments $(\sim 2 \%)$ and consequently of a small amount of titanium vacancies $(\sim 1 \%$, assuming random distribution of vacancies in the neighboring of $\mathrm{OH}$ groups and $\mathrm{F}$ atoms). The general chemical formula of the HTB phase can then be written as follows $\mathrm{Ti}_{1-\mathrm{x}} \square_{\mathrm{x}} \mathrm{O}_{1-4 \mathrm{x}}(\mathrm{F}, \mathrm{OH})_{2+4 \mathrm{x}}(\mathrm{x} \sim 0.01)$.

\section{Effect of the fluorine content.}

The aforementioned results have shown that the reactivity of titanium alkoxide toward hydrolysis and fluorolysis is dictated by the length of the alkyl chains. In this part, the reactivity of titanium alkoxide toward increasing concentration of $\mathrm{HF}$, i.e. increasing the $\mathrm{R}=\mathrm{F} / \mathrm{Ti}$ molar ratio, was investigated in the above mentioned three solvents.

Figure 5 displays the evolution of the XRD patterns of the samples obtained using ethanol as solvent while the molar ratio $\mathrm{R}=\mathrm{F} / \mathrm{Ti}$ was varied from 1.0 to 3.0. All the samples show similar diffraction patterns indexed with a tetragonal cell characteristic of anatase. Further increasing the molar ratio $\mathrm{R}$ to 3.5 did not result in any precipitate, which is due to the formation of soluble 
titanium fluorides complexes. ${ }^{9}$ Accordingly, the yield of the reaction decreases upon increasing the $\mathrm{HF}$ concentration, i.e. from $50 \%$ to $30 \%$ for $\mathrm{R}=1$ and 3 , respectively.

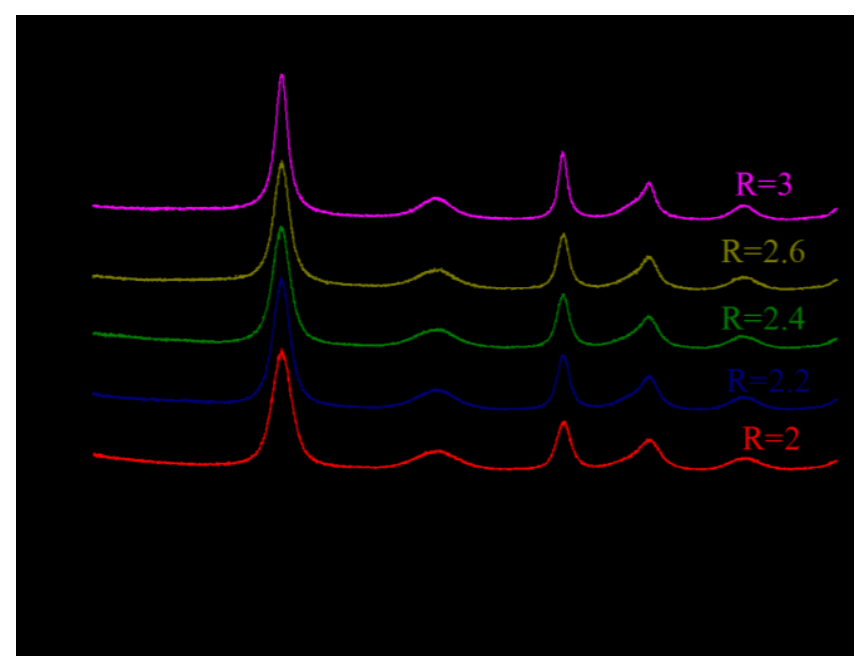

Figure 5. XRD patterns of the samples prepared using various molar ratio $\mathrm{R}=\mathrm{F} / \mathrm{Ti}$. The precursor and solvent used were $\mathrm{Ti}(\mathrm{OEt})_{4}$ and ethanol, respectively. ' $\mathrm{A}$ ' refers to anatase phase.

${ }^{19} \mathrm{~F}$ solid-state NMR spectra were recorded using a $2.5 \mathrm{~mm}$ probe head for all the samples of this series (see SI, Figure S2) and using a $1.3 \mathrm{~mm}$ probe head for three samples $(\mathrm{R}=1.0, \mathrm{R}=2.2$ and $\mathrm{R}=3$, Figure 5). The fits of these three spectra are given as SI. These spectra are similar to those of anatase $\mathrm{Ti}_{0.78} \square_{0.22} \mathrm{O}_{1.12} \mathrm{~F}_{0.40}(\mathrm{OH})_{0.48}(\mathrm{R}=2.0$, solvent: isopropanol, precursor : titanium isopropoxide, Figure 3). ${ }^{11}$ Fluorine quantification using ${ }^{19} \mathrm{~F}$ solid-state NMR spectroscopy was performed on these three samples yielding $7.1,7.8$ and 9.7 wt. $\%$ for $\mathrm{R}=1.0,2.2$ and 3.0, respectively. This indicates that increasing the molar ratio $\mathrm{R}$ yields higher fluoride concentration and thus higher titanium vacancies concentration in $\mathrm{Ti}_{1-\mathrm{x}-\mathrm{y}} \square_{\mathrm{x}+\mathrm{y}} \mathrm{O}_{2-4(\mathrm{x}+\mathrm{y})} \mathrm{F}_{4 \mathrm{x}}(\mathrm{OH})_{4 y}$, considering the preferential location of $\mathrm{F}$ close to vacancies (the stabilization of vacancies close to fluorine). ${ }^{11}$ Moreover, when the molar ratio $\mathrm{R}$ increases, the relative intensities of the NMR lines assigned to $\mathrm{Ti}_{2}-\mathrm{F}$ and $\mathrm{Ti}_{3}-\mathrm{F}$ decrease whereas the relative intensities of the NMR lines assigned to $\mathrm{Ti}_{2} \square-\mathrm{F}$ 
increase (see Figures S3-S5 and Tables S2-S4). For $\mathrm{R}=3.0$, the fluorine wt. $\%$ and the relative intensities of the NMR lines are close to those of $\mathrm{Ti}_{0.78} \square_{0.22} \mathrm{O}_{1.12} \mathrm{~F}_{0.40}(\mathrm{OH})_{0.48}$ (i. e. $10.8 \mathrm{wt} \%$ and $4 \%, 64 \%$ and $32 \%$ for $\mathrm{Ti}_{3}-\mathrm{F}, \mathrm{Ti}_{2} \square-\mathrm{F}$ and $\mathrm{Ti}_{2}-\mathrm{F}$, respectively) indicating a rather close formula.

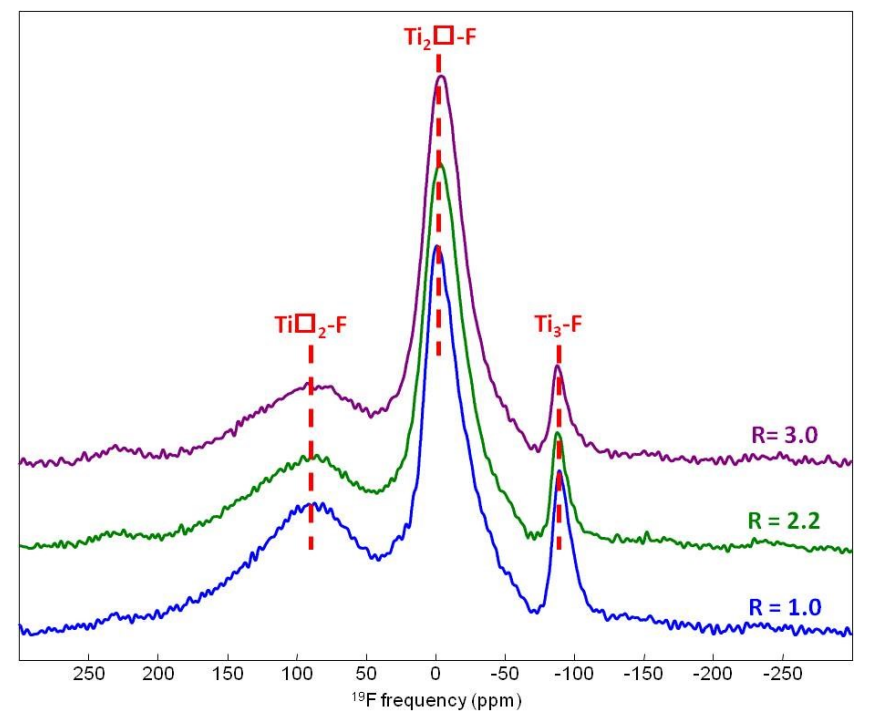

Figure 6. ${ }^{19} \mathrm{~F}$ MAS $(64 \mathrm{kHz})$ solid state NMR spectra of the samples prepared using various molar ratio $\mathrm{R}=\mathrm{F} / \mathrm{Ti}$. The precursor and solvent used were $\mathrm{Ti}(\mathrm{OEt})_{4}$ and ethanol, respectively. The red dashed lines indicate the three main NMR lines corresponding to the three fluorine species occurring in $\mathrm{Ti}_{1-\mathrm{x}-\mathrm{y}} \square_{\mathrm{x}+\mathrm{y}} \mathrm{O}_{2-4(\mathrm{x}+\mathrm{y})} \mathrm{F}_{4 \mathrm{x}}(\mathrm{OH})_{4 \mathrm{y}}$ anatase.

Figure 7 shows the evolution of the XRD patterns of the samples obtained by adjusting the fluorine content in the case of isopropanol. The molar ratio $\mathrm{R}=\mathrm{F} / \mathrm{Ti}$ was tuned from 1.0 to 3.7. Four domains can be distinguished: (i) $\mathrm{R}<2.2$, (ii) $2.2 \leq \mathrm{R} \leq 2.4$, (iii) $2.6 \leq \mathrm{R} \leq 3.5$, and (iv) $\mathrm{R}=$ 3.7. For $\mathrm{R}<2.2, \mathrm{XRD}$ patterns are indexed with a tetragonal cell (space group: I41/amd) characteristic of $\mathrm{TiO}_{2}$ anatase. The increase of $\mathrm{R}$ to 2.2 leads to the appearance of a peak located at $2 \theta=27.8^{\circ}$. This peak becomes more pronounced at $R=2.4$ and can be indexed with the HTBtype structure (space group: P63/mmc). ${ }^{16}$ The HTB phase continuously grew while R increased. 
The anatase phase disappeared at $\mathrm{R}=2.6$. Concomitantly, a peak located at $2 \theta=15.1^{\circ}$, assigned to (200) plans of $\mathrm{TiO}_{2}-\mathrm{B}$, first appeared and tended to vanish while $\mathrm{R}$ increased. An almost pure HTB-type phase was obtained at $\mathrm{R}=3.7$. Further increasing $\mathrm{R}$ to 4.0 led to the formation of soluble complexes. ${ }^{9}$ The yield of the reaction decreases upon increasing the HF concentration, i.e., from $70 \%$ to $20 \%$ for $\mathrm{R}=1$ and 3.7 , respectively. It should be noted that the powder morphology strongly evolved upon increasing R (Figure S6).

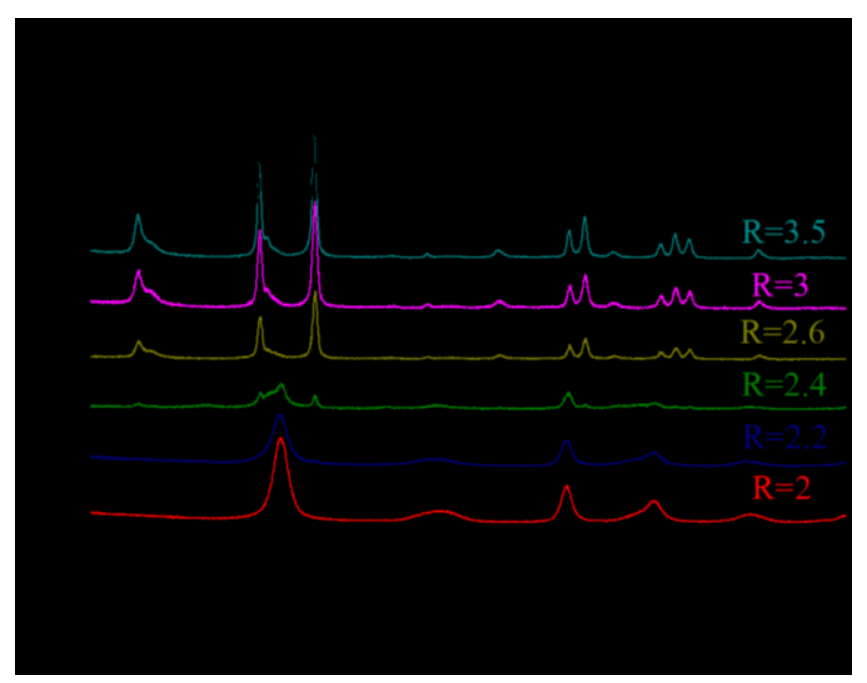

Figure 7. XRD patterns of the samples prepared using various molar ratio $\mathrm{R}=\mathrm{F} / \mathrm{Ti}$. The precursor and solvent used were titanium isopropoxide and isopropanol, respectively. 'A' and 'HTB' refer to anatase and hexagonal-tungsten-bronze type phases, respectively. Asterisks refer to (200) planes of $\mathrm{TiO}_{2}$-B.

Increasing the fluorine concentration leads to a structural change from the anatase phase $\mathrm{Ti}_{1-\mathrm{x}-}$ ${ }_{y} \square_{x+y} O_{2-4(x+y)} F_{4 x}(O H)_{4 y}$ to the fluoride-rich HTB phase $\mathrm{Ti}_{1-x} \square_{x} \mathrm{O}_{1-4 x}(F, O H)_{2+4 x}$. Thus upon increasing fluoride concentration, fluorolysis is favored over hydrolysis reaction. Nevertheless, increasing the water content favors the hydrolysis over fluorolysis thus leading to the stabilization of anatase (See SI, Figure S7). 
The evolution of the local structure of fluorine atoms during the structural change from the anatase phase $\mathrm{Ti}_{1-\mathrm{x}-\mathrm{y}} \square_{\mathrm{x}+\mathrm{y}} \mathrm{O}_{2-4(\mathrm{x}+\mathrm{y})} \mathrm{F}_{4 \mathrm{x}}(\mathrm{OH})_{4 \mathrm{y}}$ to the fluoride-rich $\mathrm{HTB}$ phase $\mathrm{Ti}_{1-\mathrm{x}} \square_{\mathrm{x}} \mathrm{O}_{1-}$ ${ }_{4 x}(\mathrm{~F}, \mathrm{OH})_{2+4 x}$ was investigated using ${ }^{19} \mathrm{~F}$ solid-state NMR. Spectra were recorded for the samples of the series with $\mathrm{R}$ ranging from to 2 to 3.7 (Figure 7). The fits of these spectra are gathered in SI (Figures S8-S14, Tables S5-S11). In agreement with XRD patterns, when R increases from 2.0 to 2.4 , the spectra show the decrease of the proportion of the anatase phase as highlighted by the decrease of the relative intensity of the line assigned to $\mathrm{Ti}_{3} \mathrm{~F}$ species. These species disappear for $\mathrm{R}=2.6$ confirming the disappearance of the anatase phase for this $\mathrm{R}$ value. When $\mathrm{R}$ increases from 2.0 to 2.2 , whereas the anatase phase remains largely predominant, the ${ }^{19} \mathrm{~F}$ NMR spectrum evolves: the proportion of $\mathrm{Ti}_{3} \mathrm{~F}$ species decreases (from $4.6 \%$ to $3.2 \%$ ) and those of $\mathrm{Ti}_{2}-\mathrm{F}$ species increases (from $35 \%$ to $38 \%$ ), i.e. the vacancy rate $(\mathrm{x}+\mathrm{y})$ increases, presumably in relation with an increase of the amount of fluorine (x), in the $\operatorname{Ti}_{1-x-y} \square_{x+y} \mathrm{O}_{2-4(x+y)} F_{4 x}(O H)_{4 y}$ anatase phase. Further increase of R destabilizes the anatase phase in favor of the HTB one which can accommodate larger amount of fluorine. At $\mathrm{R}=2.4$, the sample consists of a more balanced mixture of both the anatase and HTB phases, complicating the analysis, since on the one hand, $\mathrm{Ti}_{2}-\mathrm{F}$ species from anatase and Ti $\square$-F species from HTB, and on the other hand, $\mathrm{Ti}_{2} \square$-F species from anatase and $\mathrm{Ti}_{2}-\mathrm{F}$ species from $\mathrm{Ti}_{1-\mathrm{x}} \square_{\mathrm{x}} \mathrm{O}_{1-4 \mathrm{x}}(\mathrm{F}, \mathrm{OH})_{2+4 \mathrm{x}}$ HTB have similar chemical shift values. Nevertheless, when $\mathrm{R}$ increases from 2.2 to 2.4 , the decrease of the proportion of $\mathrm{Ti}_{3} \mathrm{~F}$ species (from $3.2 \%$ to $0.9 \%$ ) is more pronounced than the decrease of the proportion of fluorine atoms bounded to one titanium atom $\left(\mathrm{Ti} \square_{2}-\mathrm{F}\right.$ for $\mathrm{R}=2.2$ and both $\mathrm{Ti}_{2}-\mathrm{F}$ and $\mathrm{Ti} \square-\mathrm{F}$ for $\mathrm{R}=2.4$, from $38 \%$ to $22 \%$ ). Therefore, the vacancy rate and the amount of fluorine continue to increase in the anatase phase and/or the vacancy rate is especially high in the HTB phase, this second assumption being not supported by the moderate and quite stable 
proportion of $\mathrm{Ti} \square$-F species in the HTB phase for $\mathrm{R} \geq 2.6$ (in between $7 \%$ and $10 \%$ ). The rates of titanium vacancy $(\mathrm{x})$ in these $\mathrm{HTB}$ type $\mathrm{Ti}_{1-\mathrm{x}} \square_{\mathrm{x}} \mathrm{O}_{1-4 \mathrm{x}}(\mathrm{F}, \mathrm{OH})_{2+4 \mathrm{x}}$ phases, constituting mainly or exclusively the samples for $\mathrm{R} \geq 2.6$, can be estimated in between 0.04 and 0.05 .

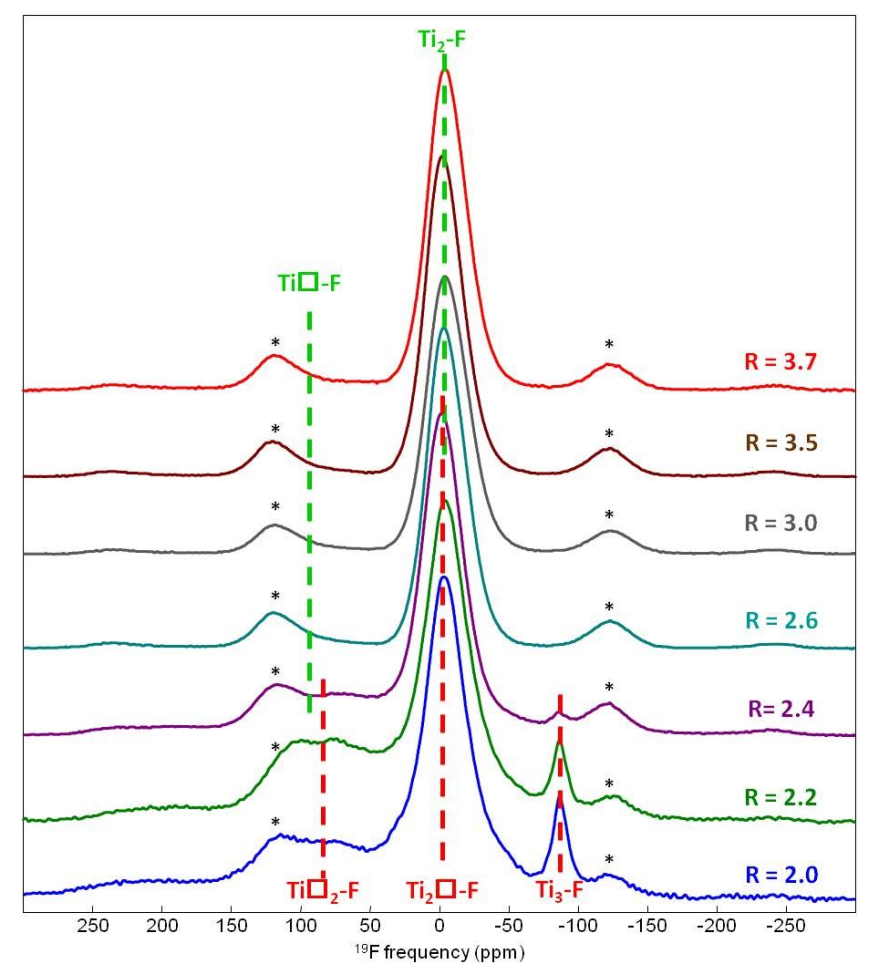

Figure 8. ${ }^{19} \mathrm{~F}$ MAS $(34 \mathrm{kHz})$ solid state NMR spectra of the samples prepared using various molar ratio $\mathrm{R}=\mathrm{F} / \mathrm{Ti}$. The precursor and solvent used were titanium isopropoxide and isopropanol, respectively. Asterisks refer to the first spinning sidebands of the main isotropic line. The red dashed lines indicate the three main NMR lines corresponding to the three fluorine species occurring in $\mathrm{Ti}_{1-\mathrm{x}-\mathrm{y}} \square_{\mathrm{x}+\mathrm{y}} \mathrm{O}_{2-4(\mathrm{x}+\mathrm{y})} \mathrm{F}_{4 \mathrm{x}}(\mathrm{OH})_{4 \mathrm{y}}$ anatase and the green dashed lines indicate the two main NMR lines corresponding to the two fluorine species occurring in HTB oxyhydroxyfluoride $\mathrm{Ti}_{1-\mathrm{x}} \square_{\mathrm{x}} \mathrm{O}_{1-4 \mathrm{x}}(\mathrm{F}, \mathrm{OH})_{2+4 \mathrm{x}}$.

Figure 9 shows the evolution of the XRD patterns of the samples obtained in 2-butanol at different R. Similarly to isopropanol, increasing the fluoride concentration yields to a structural changes from anatase to the $\mathrm{HTB}$ phase along with the minor presence of $\mathrm{TiO}_{2}-\mathrm{B}$. When $\mathrm{R}$ 
increases to 2.0, the anatase phase vanishes and the XRD pattern of the newly formed phase can be indexed with the HTB-type structure (space group: P63/mmc). Concomitantly, a peak located at $2 \theta=15.1^{\circ}$ and assigned to $\mathrm{TiO}_{2}-\mathrm{B}$ appears. Its relative intensity decreases progressively while $\mathrm{R}$ increases. The intensity of the XRD reflections of the HTB phase increases with $\mathrm{R}$, indicating that higher crystallinity of the HTB phase was obtained. For $\mathrm{R}=3.7$, sharp XRD reflections indicate the stabilization of well crystallized and pure HTB phase. No precipitate was obtained at $\mathrm{R}=4.0$, which is again due to the formation of soluble complexes at high fluorine content. ${ }^{9}$

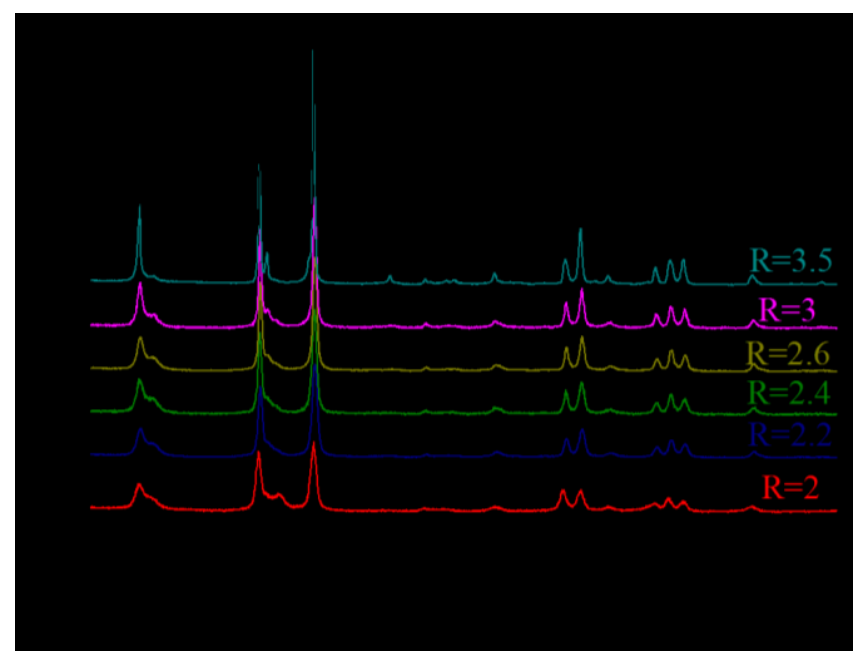

Figure 9. XRD patterns of the samples prepared using various molar ratio $R=F / T i$. The precursor and solvent used were $\mathrm{Ti}(\mathrm{OBu})_{4}$ and 2-butanol, respectively. 'A' and 'HTB' refer to anatase and hexagonal-tungsten-bronze type phases, respectively. Asterisks refer to (200) planes of $\mathrm{TiO}_{2}$-B.

The observed structural changes from anatase to the HTB phase occurred at a lower fluorine concentration in the case of 2-butanol than with isopropanol indicating an enhanced reactivity of the formed molecular precursor towards fluorine. Moreover, the use of 2-butanol enabled the 
stabilization of a well-crystallized HTB phase featuring a low content of titanium vacancies (cf. Figure 4).

${ }^{19} \mathrm{~F}$ solid-state NMR spectra were recorded for the HTB phase obtained at $\mathrm{R}=3.7$ (Figure 3) and for the anatase phase obtained at $\mathrm{R}=1.0$ (Figure 10). This last spectrum is typical of $\mathrm{Ti}_{1-\mathrm{x} \text { - }}$ y $\square_{x+y} \mathrm{O}_{2-4(x+y)} \mathrm{F}_{4 x}(\mathrm{OH})_{4 y}$ anatase phase but compared to those of $\operatorname{Ti}_{0.78} \square_{0.22} \mathrm{O}_{1.12} \mathrm{~F}_{0.40}(\mathrm{OH})_{0.48}$ (Figure 3), the proportion of $\mathrm{Ti}_{3} \mathrm{~F}$ species is higher (11\%) and those of $\mathrm{Ti} \square_{2}-\mathrm{F}$ species is lower $(27 \%), i . e$., the vacancy rate $(\mathrm{x}+\mathrm{y})$ is lower, in relation with a lower amount of fluorine $(\mathrm{x})$, in this phase. This result shows that even at low fluoride concentration, titanium alkoxide readily reacts with $\mathrm{HF}$ to stabilized fluoride in the vicinity of $\mathrm{Ti}^{4+}$. Moreover, depending on the synthesis conditions, the proportions of the different $\mathrm{Ti}_{3} \mathrm{~F}, \mathrm{Ti}_{2} \square-\mathrm{F}$ and $\mathrm{Ti} \square_{2}-\mathrm{F}$ species can be tuned.

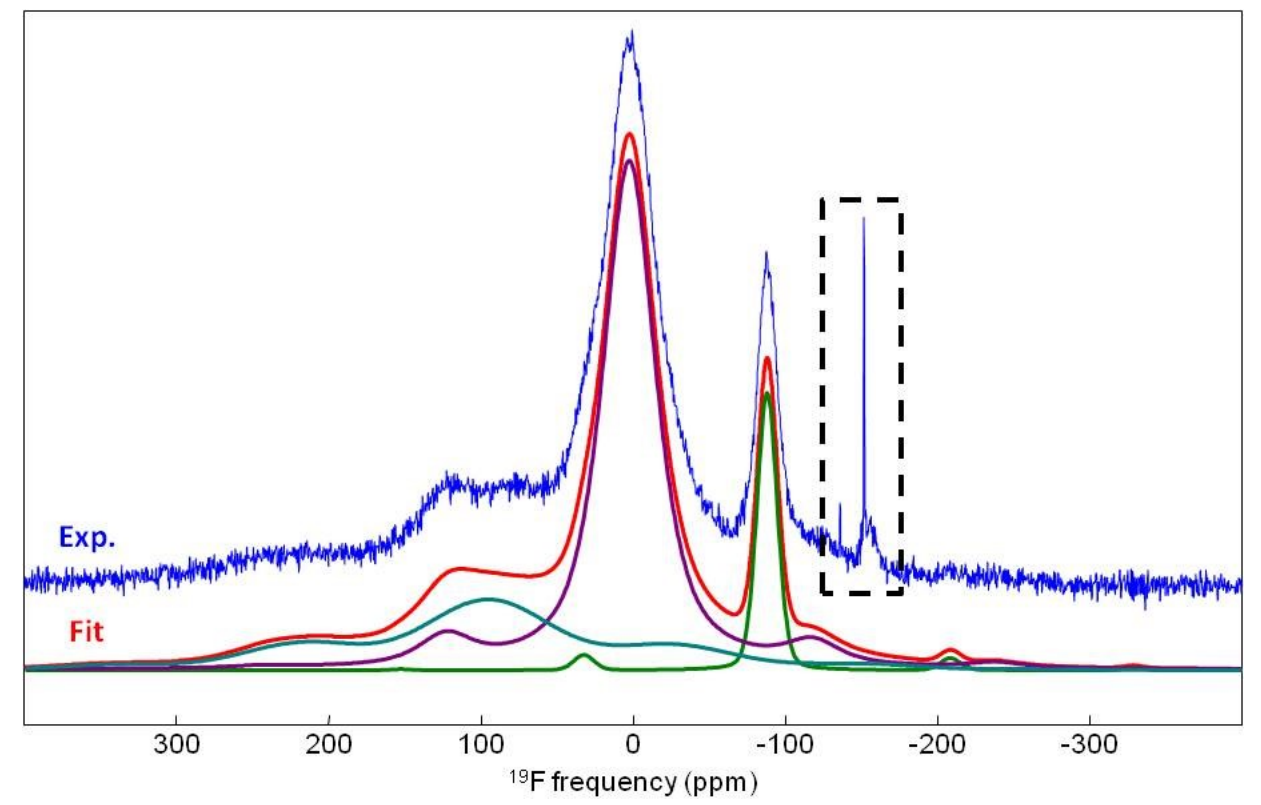

Figure 10. Experimental (blue) and fitted (red) ${ }^{19} \mathrm{~F}$ MAS (34 kHz) solid state NMR spectra of the sample prepared using $\operatorname{Ti}(\mathrm{OBu})_{4}$ as precursor, a molar ratio $\mathrm{R}$ equal to 1.0 and 2-butanol as solvent. The individual resonances used for the fit (Table S12) are shown below. The rectangle indicates unidentified impurities. 
Upon increasing the fluoride concentration, the observed structural changes (for isopropanol and 2-butanol) from anatase to the $\mathrm{HTB}$ phase along with the minor presence of $\mathrm{TiO}_{2}$ - $\mathrm{B}$ can be rationalized by the connection mode of $\mathrm{TiX}_{6}$ octahedral subunits $\left(\mathrm{X}=\mathrm{O}^{2-}, \mathrm{F}^{-}, \mathrm{OH}^{-}\right)$. At low fluoride concentration, the anatase phase having the general chemical formula $\mathrm{Ti}_{1-\mathrm{x}-\mathrm{y}} \square_{\mathrm{x}+\mathrm{y}} \mathrm{O}_{2-}$ ${ }_{4(\mathrm{x}+\mathrm{y})} \mathrm{F}_{4 \mathrm{x}}(\mathrm{OH})_{4 \mathrm{y}}$ is stabilized. Upon increasing fluoride concentration, fluorolysis increases yielding to the progressive destabilization of the anatase network. The higher content of fluoride anions in the vicinity of $\mathrm{Ti}^{4+}$ favors octahedral subunits shared by corners as found in other titanium oxy and hydroxyfluoride compounds. ${ }^{16,22,23}$ This is in good agreement with the observed phase appearance upon increasing fluorine content from edge-sharing (anatase) to both edge and corner-sharing in $\mathrm{TiO}_{2}-\mathrm{B}$ and to finally a corner-sharing configuration as found in the HTB type structure (Figure 2).

\section{Conclusion}

In summary, a systematicstudy was carried out to investigate structural and compositional effects of the sol-gel synthesis parameters on the reaction of titanium alkoxides and HF. This study provides comprehensive insights of the sol-gel process in fluorinated medium. The impact of the solvent on the reactivity of titanium alkoxide toward increasing concentration of HF showed that alcohol with longer alkyl chains such isopropanol and butanol favor fluorolysis over hydrolysis as compared to ethanol. This confirms that the solvent characteristics drastically impact on the composition/structure of the stabilized phase. Using butanol, the phase evolution upon increasing fluoride concentration enabled to prepare a pure oxyhydroxyfluoride phase featuring the HTB-type structure by favoring fluorolysis over hydrolysis reaction. The observed structural change from the anatase phase $\mathrm{Ti}_{1-x-y} \square_{x+y} \mathrm{O}_{2-4(x+y)} \mathrm{F}_{4 x}(\mathrm{OH})_{4 y}$ to the fluoride-rich HTB phase $\mathrm{Ti}_{1-\mathrm{x}} \square_{\mathrm{x}} \mathrm{O}_{1-4 \mathrm{x}}(\mathrm{F}, \mathrm{OH})_{2+4 \mathrm{x}}$ upon increasing fluoride concentration has been rationalized by the 
geometry and linking mode of the Ti building blocks. Overall, the competition between hydrolysis and fluorolysis is a paramount parameter that dictate the stabilization of oxide or fluoride-rich compounds. Finally, this work provides novel insights to control the composition of the anatase $\mathrm{Ti}_{1-\mathrm{x}-\mathrm{y}} \square_{\mathrm{x}+\mathrm{y}} \mathrm{O}_{2-4(\mathrm{x}+\mathrm{y})} \mathrm{F}_{4 \mathrm{x}}(\mathrm{OH})_{4 y}$ phase.

ASSOCIATED CONTENT

Supporting Information. Additional ${ }^{19} \mathrm{~F}$ MAS NMR spectra, fits of ${ }^{19} \mathrm{~F}$ MAS NMR spectra, SEM and TEM images and additional XRD patterns.

\section{AUTHOR INFORMATION}

\section{Corresponding Author}

*Corresponding author: damien.dambournet@upmc.fr

\section{Funding Sources}

This research was supported by European Union's Seventh Framework Programme (FP7/20072013) under REA grant agreement $n^{\circ}[321879]$ (FLUOSYNES).

\section{ACKNOWLEDGMENT}

We kindly acknowledge S. Casale for transmission electron microscopy measurement.

\section{REFERENCES}

(1) Livage, J.; Henry, M.; Sanchez, C. Prog. Solid State Chem. 1988, 18, 259-341.

(2) Nabavi, M.; Doeuff, S.; Sanchez, C.; Livage, J. J. Non-Cryst. Solids 1990, 121, 31-34.

(3) Sanchez, C.; Livage, J.; Henry, M.; Babonneau, F. J. Non-Cryst. Solids 1988, 100, 65-76. 
(4) Sanchez, C.; Boissiere, C.; Cassaignon, S.; Chaneac, C.; Durupthy, O.; Faustini, M.; Grosso, D.; Laberty-Robert, C.; Nicole, L.; Portehault, D.; Ribot, F.; Rozes, L.; Sassoye, C. Chem. Mater. 2014, 26, 221-238.

(5) Rozes, L.; Sanchez, C. Chem. Soc. Rev. 2011, 40, 1006-1030.

(6) Cargnello, M.; Gordon, T. R.; Murray, C. B. Chem. Rev. 2014, 114, 9319-9345.

(7) Yu, J. C.; Yu; Ho; Jiang; Zhang. Chem. Mater. 2002, 14, 3808-3816.

(8) Dong, Y.; Kapilashrami, M.; Zhang, Y.; Guo, J. CrystEngComm 2013, 15, 10657-10664.

(9) Menzel, R.; Duerrbeck, A.; Liberti, E.; Yau, H. C.; McComb, D.; Shaffer, M. S. P. Chem. Mater. 2013, 25, 2137-2145.

(10) Yang, H. G.; Sun, C. H.; Qiao, S. Z.; Zou, J.; Liu, G.; Smith, S. C.; Cheng, H. M.; Lu, G. Q. Nature 2008, 453, 638-641.

(11) Li, W.; Corradini, D.; Body, M.; Legein, C.; Salanne, M.; Ma, J.; Chapman, K. W.; Chupas, P. J.; Rollet, A.-L.; Julien, C.; Zhagib, K.; Duttine, M.; Demourgues, A.; Groult, H.; Dambournet, D. Chem. Mater. 2015, 27, 5014-5019.

(12) Kemnitz, E.; Groß, U.; Rüdiger, S.; Shekar, C. S. Angew. Chemie Int. Ed. 2003, 42, 4251-4254.

(13) Rüdiger, S.; Kemnitz, E. Dalton Trans. 2008, 1117-1127.

(14) Li, W.; Body, M.; Legein, C.; Dambournet, D. Inorg. Chem. 2016, 55, 7182-7187.

(15) Massiot, D.; Fayon, F.; Capron, M.; King, I.; Le Calvé, S.; Alonso, B.; Durand, J.-O.; Bujoli, B.; Gan, Z.; Hoatson, G. Magn. Reson. Chem. 2002, 40, 70-76.

(16) Demourgues, A.; Penin, N.; Dambournet, D.; Clarenc, R.; Tressaud, A.; Durand, E. J. Fluorine Chem. 2012, 134, 35-43.

(17) Fornasieri, G.; Rozes, L.; Le Calvé, S.; Alonso, B.; Massiot, D.; Rager, M. N.; Evain, M.; Boubekeur, K.; Sanchez, C. J. Am. Chem. Soc. 2005, 127, 4869-4878. 
(18) Simonsen, M. E.; Søgaard, E. G. J. Sol-Gel Sci. Technol. 2009, 53, 485-497.

(19) Li, W.; Body, M.; Legein, C.; Dambournet, D. in preparation.

(20) Silwood, C. J. L.; Abrahams, I.; Apperley, D. C.; Lockyer, N. P.; Lynch, E.; Motevalli, M.; Nix, R. M.; Grootveld, M. J. Mater. Chem. 2005, 15, 1626-1636.

(21) Lhoste, J.; Body, M.; Legein, C.; Ribaud, A.; Leblanc, M.; Maisonneuve, V. J. Solid State Chem. 2014, 217, 72-79.

(22) Vorres, K.; Donohue, J. Acta Crystallogr. 1955, 8, 25-26.

(23) Demourgues, A.; Penin, N.; Durand, E.; Weill, F.; Dambournet, D.; Viadere, N.; Tressaud, A. Chem. Mater. 2009, 21, 1275-1283. 
Insert Table of Contents Graphic and Synopsis Here

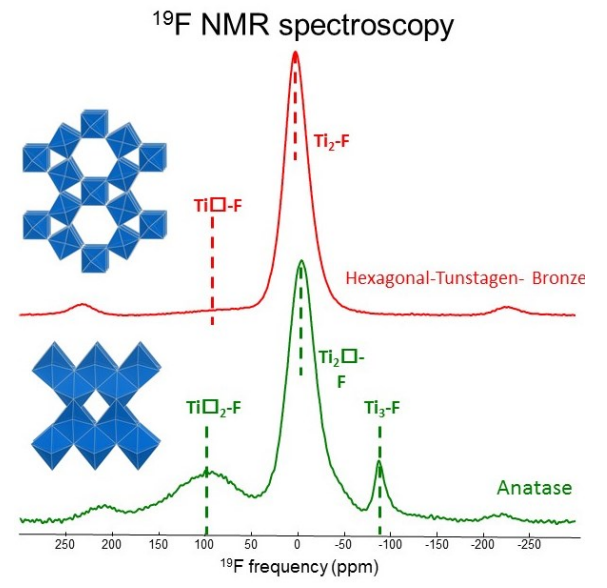

